This is a post-peer-review, pre-copyedit version of an article published in: $J$ Chem Crystallogr, 40, 888-891(2010). The final authenticated version is available online at: https://doi.org/10.1007/s10870-010-9843-2

\title{
Base-stabilized dimeric organozinc alkoxides
}

\author{
Stephan Schulz ${ }^{* a} \cdot$ Ulrich Flörke $^{b}$
}

\section{S. Schulz}

Chemistry Department, University of Duisburg-Essen, Universitätsstr. 5-7, 45117 Essen, Germany E-mail: stephan.schulz@uni-due.de; Phone: Int +201-1834635; Fax: Int + 201-1833830 
Index Abstract

\section{Base-stabilized dimeric organozinc alkoxides}

\section{Stephan Schulz ${ }^{* a} \cdot$ Ulrich Flörke $^{\mathrm{b}}$}

Single crystal X-ray analyses of two base-stabilized organozinc alkoxides [dmap-Zn(R) $\mu-O R]_{2} R=$ Et 1; $i$-Pr 2), which were obtained from reactions of $\mathrm{ZnR}_{2}$ and 4-dimethylaminopyridine (dmap) in the presence of $\mathrm{O}_{2}$, are described. 


\title{
Base-stabilized dimeric organozinc alkoxides
}

Stephan Schulz ${ }^{* a} \cdot$ Ulrich Flörke ${ }^{b}$

${ }^{a}$ Chemistry Department, University of Duisburg-Essen, Universitätsstr. 5-7, 45117 Essen, Germany

${ }^{\mathrm{b}}$ Chemistry Department, University of Paderborn, Warburger Str. 100, 33098 Paderborn, Germany

\begin{abstract}
Dimeric, base-stabilized organozinc alkoxides $[\mathrm{dmap}-\mathrm{Zn}(\mathrm{R}) \mu-\mathrm{OR}]_{2} \mathrm{R}=\mathrm{Et} \mathbf{1} ; i$-Pr 2), were obtained from reactions of $\mathrm{ZnR}_{2}$ and 4-dimethylaminopyridine (dmap) in the presence of $\mathrm{O}_{2}$. Their solid state structures were determined by single crystal X-ray diffraction studies. $\mathbf{1}$ is triclinic, space group $P-1$ with $a=8.0639(10) \AA, b=8.3082(11) \AA, c=10.4545(13) \AA, \alpha=70.846(2)^{\circ}, \beta=$ $72.316(2)^{\circ}, \gamma=81.505(2)^{\circ}$ and $\mathrm{Z}=1.2$ is triclinic, space group $P-1$ with $a=8.6381(6) \AA, b=$ 9.2773(7) $\AA, c=10.2186(7) \AA, \alpha=112.094(1)^{\circ}, \beta=103.040(1)^{\circ}, \gamma=92.598(1)^{\circ}$ and $\mathrm{Z}=1$.
\end{abstract}

Keywords Lewis-base $\cdot$ Lewis acid $\cdot$ X-ray crystal structure

Short title: Base-stabilized organozinc alkoxide 


\section{Introduction}

Zinc organometallic compounds, which were initially synthesized by Frankland almost 150 years ago [1], are valuable reagents for various applications. Alkylzinc halides are used for SimmonsSmith cyclopropanation [2], nickel-catalyzed Negishi reactions [3] and in polymerisation reactions of olefins [4]. Moreover, zinc alkoxides have been shown to effectively catalyze ring-opening polymerizations of lactide $[5,6,7,8]$, esters and ethers $[9,10,11]$ and copolymerisation of epoxides with $\mathrm{CO}_{2}[12,13]$. However, one of the earliest reactions studied in organozinc chemistry is that of zinc alkyl complexes with dioxygen. Frankland reported in 1849 on the reaction of $\mathrm{ZnEt}_{2}$ with $\mathrm{O}_{2}$,

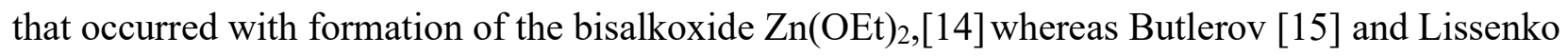
[16] reported on the formation of the partly oxygenated species $\mathrm{Zn}(\mathrm{Et}) \mathrm{OEt}$. In 1890 Demuth and Meyer demonstrated that the $\mathrm{O}_{2}$ molecule initially inserts into the $\mathrm{Zn}-\mathrm{C}$ bond with subsequent formation of the alkylperoxide $\mathrm{Zn}(\mathrm{Et}) \mathrm{OOEt}$.[17] Since then, oxygenation reactions of several $\mathrm{ZnR}_{2}$ have been investigated and the resulting complexes have been structurally characterized.[18] Recently, Lewinski et al. showed that $\mathrm{ZnMe}_{2}$ reacts with $\mathrm{O}_{2}$ with selective insertion of an oxygen atom into a single $\mathrm{Zn}-\mathrm{C}$ bond and formation of $\mathrm{Me}_{6} \mathrm{Zn}_{7}(\mathrm{OMe})_{8},[19]$ whereas the reaction of $t$ - $\mathrm{Bu}_{2} \mathrm{Zn}$ with $\mathrm{O}_{2}$ either yielded the alkoxide $[(\operatorname{thf}) \mathrm{Zn}(t-\mathrm{Bu}) \mathrm{O} t-\mathrm{Bu}]_{2}$ or the peroxide complexe [(4-MePy)Zn(t$\mathrm{Bu}) \mathrm{O} t-\mathrm{Bu}]_{2}$, depending on the Lewis base added (thf or 4-methylpyridine).[20]

We herein present the synthesis and single crystal X-ray structures of the two base-stabilized alkylzinc alkoxides $[\operatorname{dmapZn}(\mathrm{R})-\mu-\mathrm{OR}]_{2}(\mathrm{dmap}=4$-dimethylaminopyridine; $\mathrm{R}=\mathrm{Et} \mathbf{1}, i$-Pr 2), which were obtained from reactions of $\mathrm{ZnR}_{2}$ with dmap in the presence of oxygen. $\mathrm{ZnR}_{2}$ was dissolved in pentane and a solution of one equivalent dmap in pentane was added. After the reaction mixture was stirred for $30 \mathrm{~min}$ at ambient temperature under nitrogen, dry oxygen was bubbled through the solution for 2 minutes.

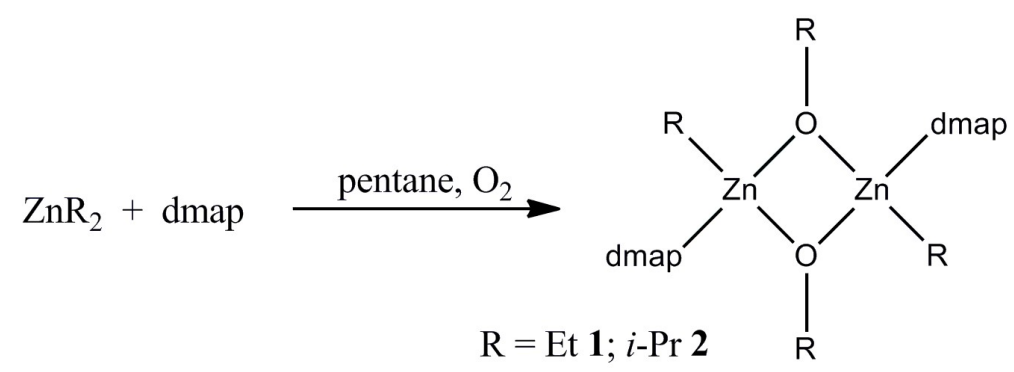

Figure 1 Synthesis of $[\mathrm{dmapZn}(\mathrm{R})-\mu-\mathrm{OR}]_{2}(\mathrm{R}=\mathrm{Et} \mathbf{1}, i-\operatorname{Pr} \mathbf{2})$.

Crystallization of $\mathbf{1}$ and $\mathbf{2}$ 
Solutions of $0.5 \mathrm{~g} 1$ and 2 in $3 \mathrm{~mL}$ of $n$-pentane were stored at $-30{ }^{\circ} \mathrm{C}$. Single crystals suitable for a single crystal X-ray analyses were obtained after 2 weeks. Table 1 illustrates the crystal data and structure refinement of $\mathbf{1}$ and $\mathbf{2}$.

\section{((Table 1 here))}

\section{Crystal structures of $\mathbf{1}$ and $\mathbf{2}$}

Data were collected on a Bruker SMART Apex-CCD diffractometer using graphite-monochromated Mo-K $\alpha$ radiation $(\lambda=0.71073 \AA)$ at $\mathrm{T}=120(2) \mathrm{K}$ and the structures were solved by Direct Methods and refined by full-matrix least-squares on $\mathrm{F}^{2}$. Semi-empirical absorption corrections from equivalents were applied. All non-hydrogen atoms were refined anisotropically and hydrogen atoms were located from $\Delta F$ maps and refined at idealized positions using a riding model with $U_{\text {iso }}(H)=$ $1.2 \mathrm{U}_{\mathrm{eq}}(\mathrm{C})$ or $1.5 \mathrm{U}_{\mathrm{eq}}(\mathrm{C}$-methyl) [21]. CCDC-773619 (1) and CCDC-773620 (2) contain the supplementary crystallographic data for this paper. These data can be obtained free of charge via www.ccdc.cam.ac.uk/data_request/cif, or by contacting The Cambridge Crystallographic Data Centre (CCDC), 12 Union Road, Cambridge CB2 1EZ, UK; fax: +44(0)1223-336033; email: deposit@,ccdc.cam.ac.uk.

\section{Results and Discussion}

Complexes 1 and $\mathbf{2}$ are formed by selective insertion of an oxygen atom into only one $\mathrm{Zn}$ - $\mathrm{R}$ bond of the initially formed adducts $\mathrm{R}_{2} \mathrm{Zn}$ (dmap). The resulting dmap-stabilized zinc alkoxides of the type dmap-Zn(R)OR subsequently dimerize with formation of the alkoxide bridged complexes $[\mathrm{dmapZn}(\mathrm{R})-\mu-\mathrm{OR}]_{2}(\mathrm{R}=\mathrm{Et} \mathbf{1}, i$-Pr 2), respectively. In contrast, Lewinski et al. obtained the bisperoxide complex [4-MePyZn $(t-\mathrm{Bu}) \mathrm{OO} t-\mathrm{Bu}]_{2}$ from the reaction of $t-\mathrm{Bu}_{2} \mathrm{Zn}$ with $\mathrm{O}_{2}$ in the presence of 4-methylpyridine.[20] Both 1 and $\mathbf{2}$ crystallize in the triclinic space group P-1, the molecules lie on crystallographic inversion centers each. Single crystals were obtained from pentane solutions of $\mathbf{1}$ and $\mathbf{2}$ after storage for two weeks at $-30{ }^{\circ} \mathrm{C}$. Central structural moiety in both compounds is the planar four-membered $\mathrm{Zn}_{2} \mathrm{O}_{2}$ ring. The $\mathrm{Zn}$ atoms are additionally coordinated by a dmap Lewis-base, hence adopting a distorted tetrahedral environment. 


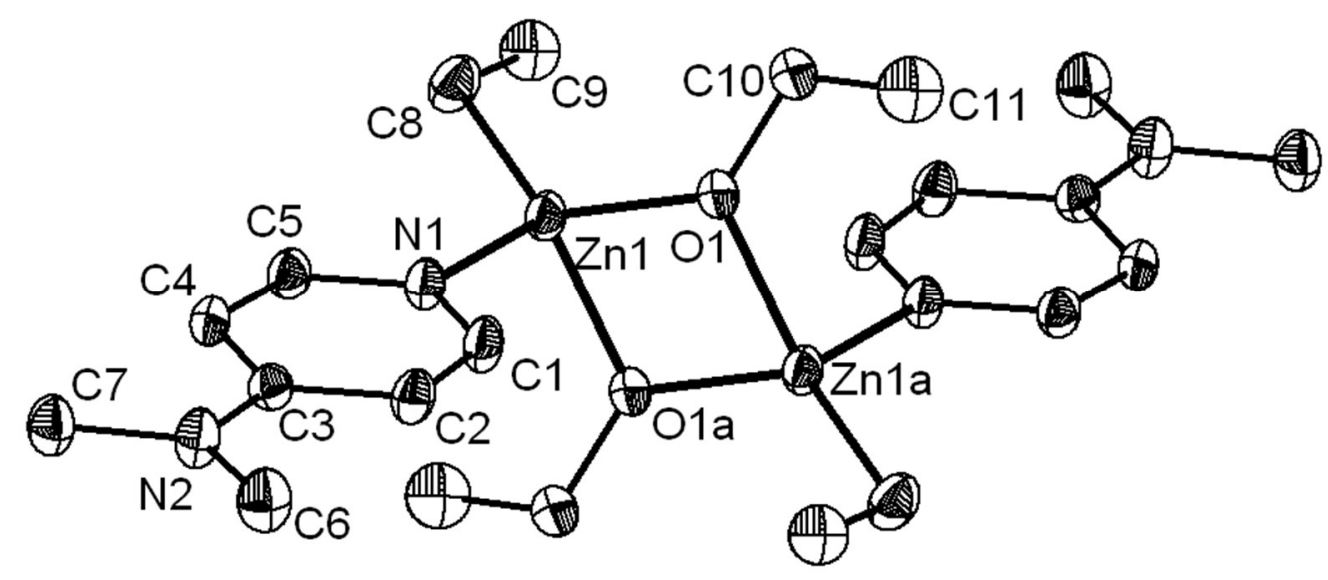

Figure 2 The molecular structure and atom-numbering scheme for $[\mathrm{dmapZn}(\mathrm{Et})-\mu-\mathrm{OEt}]_{2} \mathbf{1}$.

Displacement ellipsoids are drawn at the $50 \%$ probability level and $\mathrm{H}$ atoms are omitted for clarity.

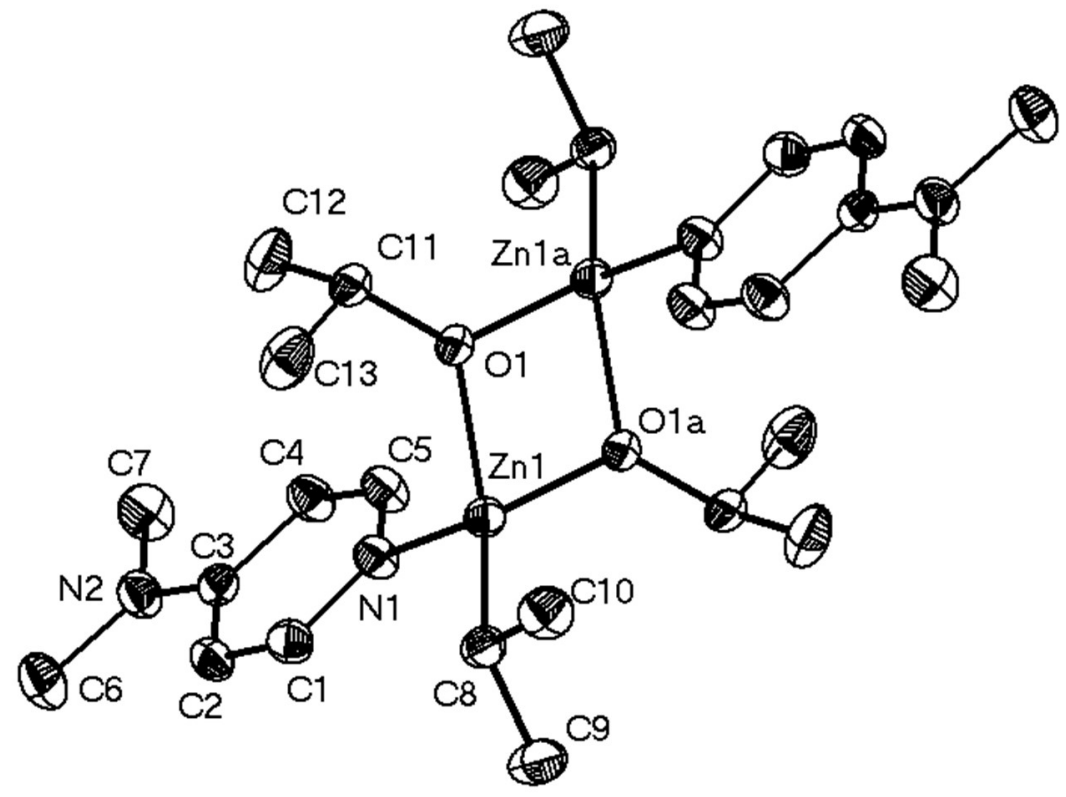

Figure 3 The molecular structure and atom-numbering scheme for $[\mathrm{dmapZn}(i-\operatorname{Pr})-\mu-\mathrm{O} i-\operatorname{Pr}]_{2} \mathbf{2}$.

Displacement ellipsoids are drawn at the $50 \%$ probability level and $\mathrm{H}$ atoms are omitted for clarity.

The Zn-O (av. 2.000(2) 1, 1.989(1) $2 \AA$ ) and Zn-C bond lengths (1.986(2) 1, 2.000(2) $\AA$ 2) are within the expected range. The $\mathrm{Zn}-\mathrm{N}$ bond lengths, which are almost identical (2.100(2) 1, 2.111(2) $\AA \AA$ 2), are also typical for this type of compound. Pyridine-stabilized alkylzinc alkoxide complexes, which were recently reported [22], show comparable structural parameters. The different $\mathrm{Zn}-\mathrm{O}-\mathrm{Zn}$ $\left(97.9(1) 1 ; 99.7(1)^{\circ} 2\right)$ and O-Zn-O bond angles $\left(82.1(1) 1 ; 80.3(1)^{\circ} 2\right)$ reflect the different steric demand of the alkyl substituents bound to the Zn atoms. $i$-Pr groups are sterically bulkier substituent compared to Et groups, hence decreasing the endocyclic O-Zn-O and increasing the $\mathrm{Zn}$ $\mathrm{O}-\mathrm{Zn}$ and bond angles. 
Acknowledgments Stephan Schulz gratefully acknowledges financial support by the German Research Foundation.

\section{References}

[1] Frankland E, Duppa BF (1864). J Chem Soc 17:29.

[2] Sawada S, Inouye Y (1969). Bull Chem Soc Jpn. 42:2269.

[3] Zhou JR, Fu GC (2003). J Am Chem Soc 125:14726.

[4] Hsieh, HL (1976). J Polym Sci Polym Chem Ed 14:379.

[5] Chamberlain BM, Cheng M, Moore DR, Ovitt TM, Lobkovsky EB, Coates GW (2001). J Am Chem Soc 123:3229.

[6] Chakraborty D, Chen EY-X (2003). Organometallics 22:769.

[7] Chisholm MH, Gallucci JC, Phomphrai K (2005). Inorg Chem 44:8004.

[8] Chen H-Y, Tang H-Y, Lin, C-C (2006). Macromolecules 39:3745.

[9] Walker DA, Woodman TJ, Schormann M, Hughes DL, Bochmann M (2003). Organometallics $22: 797$.

[10] Sarazin Y, Schormann M, Bochmann M (2004). Organometallics 23:3296.

[11] Sarazin Y, Howard RH, Hughes DL, Humphrey SM, Bochmann M (2006). Dalton Trans. 340.

[12] Byrne CM, Allen SD, Lobkovsky EB, Coates GW (2004). J Am Chem Soc 126:11404.

[13] Eberhardt R, Allmendinger M, Luinstra GA, Rieger B (2003). Organometallics 22:211.

[14] Frankland E (1849). Justus Liebigs Ann Chem 71:171.

[15] Butlerov A (1864). Z. Pharm Chem 7:402.

[16] Lissenko A (1864). Jahresber Pharm 470.

[17] Demuth R, Meyer V (1890). Ber Dtsch Chem Ges 23:394.

[18] Jastrzebski JTBH, Boersma J, van Koten G in Patai's Chemistry of Functional Groups;

Organozinc Compounds (2007). Ed. Rappoport Z, John Wiley\& Sons 2009. DOI:

10.1002/9780470682531.pat0365.

[19] Lewinski J, Marciniak W, Lipkowski J, Justyniak I (2003). J Am Chem Soc 125:12698.

[20] Lewinski J, Sliwinski W, Dranka M, Justyniak I, Lipkowski J (2006). Angew Chem 118:4944.

[21] Data collection: SMART (Version 5.62), SAINT (Version 6.02), and SADABS (Version 2.03). Bruker AXS Inc., (2002). Madison, Wisconsin, USA. Structure solution and refinement: Sheldrick G (2008). Acta Cryst. A64:112.

[22] Sarazin Y, Wright JA, Harding DAJ, Martin E, Woodman TJ, Hughes DL, Bochmann M (2008). J Organomet Chem 693:1494. 
Table 1 Crystal data and structure refinement of 1

CCDC deposit no.

Empirical formula

Formular weight

Temperature

Wavelength

Crystal system

Space group

Unit cell dimensions

Volume

$Z$

Density (calculated)

Absorption coefficient

$\mathrm{F}(000)$

Crystal size
773619

$\mathrm{C}_{22} \mathrm{H}_{40} \mathrm{~N}_{4} \mathrm{O}_{2} \mathrm{Zn}_{2}$

523.32

120(2) K

$0.71073 \AA$

Triclinic

P-1

$\mathrm{a}=8.0639(10) \AA$

$\mathrm{b}=8.3082(11) \AA$

$\mathrm{c}=10.4545(13) \AA$

$\alpha=70.846(2)^{\circ}$

$\beta=72.316(2)^{\circ}$

$\gamma=81.505(2)^{\circ}$

629.48(14) $\AA^{3}$

1

$1.381 \mathrm{Mg} \mathrm{m}^{-3}$

$1.929 \mathrm{~mm}^{-1}$

276

$0.38 \times 0.35 \times 0.27 \mathrm{~mm}$
773620

$\mathrm{C}_{26} \mathrm{H}_{48} \mathrm{~N}_{4} \mathrm{O}_{2} \mathrm{Zn}_{2}$

579.42

120(2) K

$0.71073 \AA$

triclinic

P-1

$\mathrm{a}=8.6381(6) \AA$

$\mathrm{b}=9.2773(7) \AA$

$\mathrm{c}=10.2186(7) \AA$

$\alpha=112.094(1)^{\circ}$

$\beta=103.040(1)^{\circ}$

$\gamma=92.598(1)^{\circ}$

731.47(9) $\AA^{3}$

1

$1.315 \mathrm{Mg} \mathrm{m}^{-3}$

$1.667 \mathrm{~mm}^{-1}$

308

$0.35 \times 0.27 \times 0.22 \mathrm{~mm}$

$28.08^{\circ}$

$-10 \leq \mathrm{h} \leq 10,-10 \leq \mathrm{k} \leq 10,-13 \leq \mathrm{l} \leq 13 \quad-11 \leq \mathrm{h} \leq 11,-12 \leq \mathrm{k} \leq 12,-13 \leq \mathrm{l} \leq 11$ 6058

7365

$2983\left(\mathrm{R}_{\text {int }}=0.0197\right)$

$3518\left(\mathrm{R}_{\text {int }}=0.0224\right)$

$98.9 \%$

$98.5 \%$

0.6240 and 0.5277

0.7106 and 0.5931

Full-matrix least-squares on Full-matrix least-squares on $F^{2}$ $F^{2}$

Data/restraints/parameters

$2983 / 0 / 126$

$3518 / 0 / 154$

goodness-of-fit on $F^{2}$

1.050

1.056

Final $R$ indices $[I>2 \operatorname{sigma}(I)]$

$R 1=0.0355, w R 2=0.0889$

$R 1=0.0299, w R 2=0.0734$

$R 1=0.0402, w R 2=0.0913$

$R 1=0.0341, w R 2=0.0735$

Largest diff. peak and hole

0.870 and -0.680 e $\AA^{-3}$

0.494 and -0.221 e $\AA^{-3}$ 
Table 2. Selected geometric parameters $\left(\AA,^{\circ}\right)$.

\begin{tabular}{llll}
\hline & 1 & & $\mathbf{2}$ \\
\hline Zn1-O1 & $1.9883(16)$ & Zn1-O1 & $1.9906(12)$ \\
Zn1-O1a & $2.0111(16)$ & Zn1-O1a & $1.9873(12)$ \\
Zn1-C8 & $1.986(2)$ & Zn1-C8 & $2.0000(18)$ \\
Zn1-N1 & $2.1000(19)$ & Zn1-N1 & $2.1109(15)$ \\
O1-C10 & $1.400(3)$ & O1-C11 & $1.408(2)$ \\
& & & \\
O1-Zn1-O1a & $82.12(7)$ & O1-Zn1-O1a & $80.32(5)$ \\
Zn1-O1-Zn1a & $97.88(7)$ & Zn1-O1-Zn1a & $99.68(5)$ \\
O1-Zn1-N1 & $98.67(7)$ & O1-Zn1-N1 & $102.43(6)$ \\
O1-Zn1-C8 & $128.25(9)$ & O1-Zn1-C8 & $128.00(7)$ \\
C8-Zn1-N1 & $114.48(9)$ & C8-Zn1-N1 & $112.91(7)$ \\
\hline
\end{tabular}




\section{DuEPublico}

This text is made available via DuEPublico, the institutional repository of the University of Duisburg-Essen. This version may eventually differ from another version distributed by a commercial publisher.

DOI: $\quad 10.1007 / \mathrm{s} 10870-010-9843-2$

URN: urn:nbn:de:hbz:464-20201104-082846-7

This is a post-peer-review, pre-copyedit version of an article published in:

J Chem Crystallogr, 40, 888-891(2010). The final authenticated version is available online at: https://doi.org/10.1007/s10870-010-9843-2

All rights reserved. 